\title{
Top-Down Regulation of Litter Invertebrates by a Terrestrial Salamander
}

Bernard Michael Walton

Cleveland State University, b.walton@csuohio.edu

Follow this and additional works at: https://engagedscholarship.csuohio.edu/scibges_facpub

Part of the Animal Sciences Commons, and the Biology Commons

How does access to this work benefit you? Let us know!

\section{Recommended Citation}

Walton, Bernard Michael, "Top-Down Regulation of Litter Invertebrates by a Terrestrial Salamander" (2013). Biological, Geological, and Environmental Faculty Publications. 99.

https://engagedscholarship.csuohio.edu/scibges_facpub/99

This Article is brought to you for free and open access by the Biological, Geological, and Environmental Sciences Department at EngagedScholarship@CSU. It has been accepted for inclusion in Biological, Geological, and Environmental Faculty Publications by an authorized administrator of EngagedScholarship@CSU. For more information, please contact library.es@csuohio.edu. 


\title{
TOP-DOWN REGULATION OF LITTER INVERTEBRATES BY A TERRESTRIAL SALAMANDER
}

\author{
B. Michael Walton ${ }^{1}$ \\ Department of Biological, Geological and Environmental Sciences, Cleveland State University, \\ Cleveland, $\mathrm{OH} 44115$, USA
}

\begin{abstract}
Aвstract: Terrestrial plethodontid salamanders are abundant predators within the forest floor litter of eastern North America, and are hypothesized to regulate soil and litter invertebrate density and species composition. I tested this hypothesis during a 6-yr study of the effects of the Eastern Red-backed Salamander (Plethodon cinereus) on the invertebrate community of a forest site in northeast Ohio. Salamander surface density, invertebrate abundance, and community composition were monitored within 30 open, circular plots. Variation in plot occupancy by $P$. cinereus was achieved by supplying plots with differing amounts of artificial cover $(0,1$, or 4 ceramic tiles) that served as refuges for the salamanders. Salamander plot occupancy, invertebrate density, leaf litter mass, and leaf litter moisture were quantified each spring and fall from 2003 through 2008. Statistically significant effects of salamander plot-occupancy on invertebrate densities were found for several taxa of mesofauna, including several Collembola taxa, oribatid mites, pseudoscorpions, and psocoptera. The strength and direction of salamander effects varied among taxa and included negative, positive, and no effects on invertebrate densities. The magnitude and sign of salamander effects on invertebrate densities were predicted by seasonal and interannual variation in leaf litter mass and, to a lesser extent, litter moisture content. Salamander effects decreased with increasing litter mass and were more often negative when litter mass was high, whereas positive effects on invertebrate densities were more likely when litter mass was low. For several taxa, the positive effect of $P$. cinereus also increased with litter moisture. I propose two mechanistic hypotheses for these dynamics that integrate behavioral ecology of salamander prey selection and territorial defense with variation in litter mass and litter moisture.
\end{abstract}

Key words: Eastern Red-backed Salamander; Food web; Interaction strength; Plethodon cinereus; Prey switching; Territoriality

Terrestrial plethodontid salamanders are hypothesized to exert top-down effects on invertebrate communities, litter decomposition, and nutrient cycling within forest floor food webs of eastern North America (Burton and Likens, 1975a,b; Hairston, 1987; Petranka, 1998; Davic and Welsh, 2004). Hairston (1987) suggested that terrestrial plethodontids should have an "appreciable" indirect effect upon leaf litter decomposition through salamander predation on invertebrates that consume saprophytic fungi. The remarkably high abundance and biomass often reported for plethodontids (Burton and Likens, 1975a) gives force to this hypothesis. Hairston (1987) estimated that prey consumption by plethodontid communities can exceed one complete turnover of litter and soil invertebrate fauna annually, further highlighting the potential for regulation of invertebrate species composition and ecological processes. Indeed, Hairston's (1987) estimate is nearly three-fold

\footnotetext{
${ }^{1}$ Correspondence: e-mail, b.walton@csuohio.edu
}

greater than the estimated prey consumption of forest floor spiders (Moulder and Reichle, 1972), a group that exerts top-down effects on invertebrate abundance and leaf litter decomposition rates (Lawrence and Wise, 2000, 2004; Lensing and Wise, 2006).

However, studies that have sought to quantify the effects of terrestrial plethodontids on lower trophic levels have produced equivocal findings, including negative, positive, and no effect on invertebrate density. Wyman (1998) found that the Eastern Redbacked Salamander, Plethodon cinereus, in field enclosures reduced densities of several macroinvertebrate taxa in comparison to control enclosures lacking salamanders. During the first $2 \mathrm{yr}$ of the experiment reported upon here, I recorded reductions of several mesofaunal taxa within plots occupied by $P$. cinereus in comparison to plots not occupied by the salamanders, but I observed no effects of salamanders on macroinvertebrate taxa (Walton, 2005). Rooney et al. (2000), however, reported increases of Collembola in field enclosures with $P$. cinereus in contrast to 
control enclosures without salamanders, a result they attributed to salamander consumption of ants, a predator of Collembola. In a pair of experiments conducted in laboratory microcosms, Walton and Steckler (2005) and Walton et al. (2006) recorded both negative and positive effects on invertebrate densities. The presence of $P$. cinereus within microcosms was associated with reductions of macroinvertebrate detritivores (Walton and Steckler, 2005; Walton et al., 2006) and pseudoscorpions (Walton et al., 2006), but also substantial increases among oribatid mites and several taxa of Collembola. In these cases, increases in mesofauna were attributed to indirect effects of salamander predation that mediated outcomes of competitive and predator-prey interactions among invertebrates within the microcosms. Homyack et al. (2010), however, reported no effects of $P$. cinereus on invertebrate densities during a 2yr experiment in field enclosures.

Previous studies also differ as to whether salamanders affected leaf litter decomposition. Wyman (1998) reported that the presence of $P$. cinereus in field enclosures reduced the rate of beech litter mass loss, which he attributed to salamander-mediated reductions of macroinvertebrates that fragment leaf litter. Walton and Steckler (2005), however, observed no difference in mass loss of mixedspecies leaf litter between microcosms with and without $P$. cinereus. Walton and Steckler (2005) suggested that the potential effect of salamander-mediated reductions of macroinvertebrate detritivores on litter mass loss was offset by reciprocal increases in mesofaunal microbi-detritivores. Homyack et al. (2010) also found no indirect effect of $P$. cinereus on litter decomposition.

These discrepancies may reflect artifacts of differences in experimental approaches (e.g., field enclosures vs. microcosms), a preponderance of short-term studies, or inappropriate statistical analysis (Walton et al., 2006; Homyack et al., 2010). However, an alternative view is that the prior studies reflect ecologically relevant dynamics that differ because of variation among studies in environmental conditions or invertebrate community composition (Walton et al., 2006). Indeed, remarkably similar variability in experimental outcomes has been reported for the top-down effects of arthropod predators. For example, spiders have been found variously to reduce (Lawrence and Wise, 2000; Wise, 2004; Miyashita and Niwa, 2006), increase (Lensing and Wise, 2006; Schultz et al., 2006), and have no effect (Schultz et al., 2006) on densities of Collembola within forest litter, as well as to have contrasting effects on litter decomposition within even the same study locality (Lawrence and Wise, 2000, 2004). As with terrestrial salamanders, the causes of this variation are not fully understood, but have been associated with complex interactions among precipitation, drainage properties of forest soils, and changes in Collembola behavior in response to hydric conditions and availability of fungal resources (Lawrence and Wise, 2004; Lensing and Wise, 2006; Schultz et al., 2006). Hence, the magnitude and direction of top-down effects of arthropod predators seem contingent upon microclimate and bottom-up conditions of moisture content and resource availability. Since plethodontids participate in the same food web, it stands to reason that salamander-mediated dynamics may also vary with prevailing environmental conditions.

In this report, I present results of a $6-\mathrm{yr}$ investigation of the impact of $P$. cinereus on invertebrate communities within open forest floor plots. The objectives of the study were to (1) test the general hypothesis that $P$. cinereus exerts top-down effects on the forest floor invertebrate community, (2) characterize the strength and direction of salamander-mediated effects, and (3) determine the extent to which salamander-mediated effects vary with several sources of environmental heterogeneity (e.g., salamander density, invertebrate densities, leaf litter thickness, and litter moisture content). An additional objective was to determine if dynamics observed previously in field enclosures and laboratory microcosms are also at work in an unrestricted field setting. In this report, I document seasonal and interannual variation in the strength and direction of top-down effects exerted by $P$. cinereus. Further, I suggest possible mechanisms for these dynamics based upon variation in salamander prey selection and costs of territorial defense in 
response to variation in invertebrate community composition and thickness and moisture content of the litter layer.

\section{Material and Methods}

\section{Study Site, Plot Surveys, and Invertebrate Quantification}

This study was conducted at a forest site within the Cuyahoga Valley National Park, Summit County, Ohio $\left(41^{\circ} 13^{\prime} 46.94^{\prime \prime} \mathrm{N}\right.$, $81^{\circ} 31^{\prime} 4.01^{\prime \prime} \mathrm{W}$; datum = WGS84). The site lays on a ridge top (elevation $\approx 268 \mathrm{~m}$ ) bounded by two ephemeral headwater streams within mixed mesophytic deciduous forest dominated by Acer saccharum (Sugar Maple), Fagus grandifolia (American Beech), Liriodendron tulipifera (Tulip Poplar), and Quercus rubra (Red Oak).

In April 2002, I established 30 open, circular plots in a 3-plot $\times 10$-plot rectangular array with the long side of the array perpendicular to the north-south axis of the ridgetop. Plot boundaries were separated by approximately $3 \mathrm{~m}$. Each plot was marked with a metal stake at plot center, about which a 1-m radius $\left(\approx 3.14 \mathrm{~m}^{2}\right.$ area) was monitored, as described in following sections. Artificial cover objects (ACOs) in the form of ceramic floor tiles $(19.7 \mathrm{~cm} \times 19.7 \mathrm{~cm})$ were distributed randomly among plots to create three treatments of 10 replicates each: (1) natural cover, i.e., litter and woody debris, no ACOs; (2) one ACO at plot center, $0.04 \mathrm{~m}^{2}$ of artificial cover; (3) four ACOs arranged in a $39.4 \mathrm{~cm} \times 39.4$ $\mathrm{cm}^{2}$ at plot center, $0.16 \mathrm{~m}^{2}$ of artificial cover. The ceramic tiles mimicked flat rocks, which are often the preferred cover of $P$. cinereus (Moore et al., 2001; Richmond and Trombulak, 2009). The local soil type, Geeburg silt loam C2, is characterized by few stony fragments (NRCS, 2012a,b). Leaf litter and woody debris are the only natural cover available within the plot array. Moreover, $P$. cinereus have been found to prefer larger cover objects (Mathis, 1990; Richmond and Trombulak, 2009). Hence, I hypothesized that the number of salamanders occupying the plots would increase with the number of ACOs among treatments.

I sampled the plots twice yearly, once in spring and once in autumn. The sampling periods were selected to coincide with bimodal peaks of $P$. cinereus surface activity (Pfingsten and Downs, 1989) and to differ substantially in the amount of leaf litter. Leaf litter layer is thick in spring because low winter temperatures and snow cover slow decomposition of leaf litter deposited the preceding fall. Spring sampling was conducted in mid-May to allow at least 1 mo of interaction between salamanders and forest floor invertebrates following spring emergence. The fall sample was conducted prior to significant leaf fall at the approximate annual nadir of leaf litter thickness. I visited the site just once per season to reduce possible sampling disturbance effects on salamander activity and invertebrate abundance (e.g., Marsh and Goicochea, 2003).

Sampling began at each plot by taking a sample of leaf litter down to the soil surface using a circular sampling frame $\left(189 \mathrm{~cm}^{2}\right)$ placed within $0.5 \mathrm{~m}$ of the plot center point. Litter samples were placed into plastic bags and sealed for return to the laboratory. The location within the plot from which the litter sample was taken was varied so that the same location was not sampled twice within the same year. The plot was searched for $P$. cinereus by turning cover objects and sorting through leaf litter within a $1-\mathrm{m}$ radius of the plot center. The area surveyed for each plot $\left(\approx 3.14 \mathrm{~m}^{2}\right)$ was chosen to be within estimates of home range for $P$. cinereus (Kleeberger and Werner, 1982; Mathis, 1990, 1991; Liebgold and Jaeger, 2007). To measure snout-vent length (SVL), I placed a salamander into a clear plastic bag and gently manipulated the animal to an edge of the bag and into a straightened and immobilized position. SVL was measured with a caliper or ruler from the tip of the animal's snout to the anterior edge of its vent. All salamanders were placed back into the plot within 5 min of capture. Litter samples were weighed on an electronic balance to the nearest $0.01 \mathrm{~g}$ to obtain wet weight. Invertebrates were separated from the litter by Berlese extraction for $4 \mathrm{~d}$ to into $70 \%$ ethanol. Upon completion of extraction, litter samples were dried in an oven at $60^{\circ} \mathrm{C}$ to constant mass, and then reweighed to obtain dry mass and to calculate moisture content. 
Invertebrates were identified and counted under a binocular microscope.

\section{Efficacy of ACO Manipulation}

I used ordinal logistic regression to determine if the number of $P$. cinereus per plot increased with the number of ACOs and to investigate the effects of leaf litter amount and moisture content on salamander plot occupancy. For each of the 12 sampling periods, seven regression models were examined representing all possible regressions, i.e., three models for the single effect of each independent variable (ACO number, mass of dried leaf litter, and percent moisture content of leaf litter), three two-independent-variable models, and one model including all three independent variables $(N=30$ plots for all models). If ACOs were an important determinant of salamander occupancy of plots, then the model (or models) that best fit the data would be those that included a positive ACO effect.

Akaike Information Criteria corrected for small sample size $\left(\mathrm{AIC}_{\mathrm{C}}\right)$ were used to select among competing models (Burnham and Anderson, 2002) for the model that best fit the data, i.e., the model yielding the minimum $\mathrm{AIC}_{\mathrm{C}}\left(\mathrm{AIC}_{\mathrm{Cmin}}\right) . \mathrm{AIC}_{\mathrm{C}}$ for model $i-\mathrm{AIC}_{\mathrm{Cmin}}$ $\left(\Delta_{i} \quad \mathrm{AIC}_{\mathrm{C}}\right)$ was used to calculate relative likelihood, $\exp \left(-1 / 2 \Delta_{i} \quad \mathrm{AIC}_{\mathrm{C}}\right)$ and Akaike weights $\left(\omega_{i}=\right.$ relative likelihood for model $i /$ sum of relative likelihood for all models within a sampling period). Evidence ratios $\left(\omega_{i} / \omega_{\min }\right)$ were used to assess the relative probability of each alternative model compared to the model yielding $\mathrm{AIC}_{\mathrm{Cmin}}$. Predicted probabilities for the occurrence of one or more salamanders within ACO classes $(0,1$, and 4) were obtained from the ordinal regression model that best fit the data.

For P. cinereus, persistence of cover object use, fidelity to home range, and the strength of territorial defense are related to body size (Mathis, 1990; Moore et al., 2001; Ousterhout and Liebgold, 2010), such that larger adult individuals are more likely to occupy cover objects and defend territories than juveniles or smaller adults. Therefore, body size should be an indirect indicator of persistence of plot occupancy. If ACOs promoted long-term, persistent territorial occupancy by $P$. cinereus, then salamanders occurring under ACOs should be adults and larger than salamanders occurring within natural cover. Further, if the largest individuals obtained the largest cover objects (e.g., Mathis, 1990; Hickerson et al., 2004) then body size of salamanders should increase with the number of ACOs within plots. To test these hypotheses, I compared SVL among ACO treatments with analysis of variance (ANOVA). Salamanders were considered adults if SVL exceeded $30 \mathrm{~mm}$ (Maglia, 1996).

To determine if ACOs introduced bias with regard to leaf litter amount or litter moisture, I used multivariate repeated-measures (ANOVA) to test for ACO-related differences in log-transformed leaf litter mass and arcsinsquare root transformed percentage of litter moisture. The ACO treatment was the between-subject effect; season and year were repeated within-subject effects. I tested for ACO-related bias on invertebrate densities using doubly multivariate repeated-measures (ANOVA) in which the dependent variables were five principal components derived from log-transformed invertebrate density data (as described in the following section).

\section{Salamander and Environmental Effects on Invertebrate Community Composition}

Analyses of invertebrate densities were confined to those taxa accounting for at least $0.5 \%$ of total invertebrate abundance (see Supplementary Appendix) to minimize the potential for bias from an excess of zero counts within the data matrix (Sileshi, 2008). Dimensionality of the analyses was reduced further by obtaining principal components of the invertebrate abundance data, thereby reducing the potential for Type I error and improving normality of the abundance dimensions. Principal components with eigenvalues greater than one were retained for subsequent analysis. Taxa with factor loadings $\geq 0.50$ on principal components were used to characterize and interpret the principal components.

A repeated-measures design was not possible for the analysis of salamander effects on invertebrate densities, because salamander occupancy varied among sampling dates. Rather, the principal component scores were analyzed with multivariate analysis of covari- 
ance (MANCOVA) in which salamander occupancy (salamander present or absent), season, and year were fixed effects and logtransformed dry litter mass and arcsin-square root transformed percentage of litter moisture served as covariates. The MANCOVA provided a single, communitywide, omnibus Fstatistic testing for salamander occupancy effects on invertebrate abundance. A significant omnibus effect of salamander occupancy within the MANCOVA was the criterion for further exploration of individual principal components and invertebrate taxa, which proceeded through a two-step process. First, univariate analyses of covariance (ANCOVAs) were conducted for each principal component. Second, principal components showing a statistically significant response to salamander occupancy were further dissected by examining ANCOVAs for taxa with factor loadings $\geq$ 0.50 .

Multiple ANCOVAs performed upon the principal components and individual taxa increased the risk of Type I error. However, strict adherence to standard Type I error reduction methods (e.g., Bonferroni correction) can impose a heavy burden upon community-level studies, because the ability to detect biologically relevant effects declines with the number of taxa analyzed (Moran, 2003; Nakagawa, 2004). To address this issue, I calculated the probability $p$ of finding $K$ significant results from $N$ individual tests, assuming the conventional criterion $(\alpha=0.05)$ for rejecting the null hypothesis of no response to treatment effects, according to Moran's (2003) equation:

$$
p=[N ! /(N-K) ! K !] \alpha^{K}(1-\alpha)^{N-K} .
$$

I assumed a significant omnibus $F$-test for the multivariate analysis, coupled with a value for Moran's $p \leq 0.05$ for results of multiple ANCOVAs, to be sufficient evidence of a biologically relevant result. Statistical analyses were conducted using IBM SPSS, version 18.0.

The process described above yielded a set of taxa that were responsive to salamander effects. These "responder taxa" were investigated further to characterize the relationships among the strength and direction of salamander effects and seasonal and interannual variation in litter mass and percentage of litter moisture. Salamander effects were calculated as per capita interaction strength $I$, according to Wootton (1997):

$$
I=\ln \left(\frac{D_{o}}{D_{u}}\right) / S
$$

where $D_{o}$ is density of an invertebrate taxon within plots occupied by $P$. cinereus, averaged over the number of occupied plots on a sampling date; $D_{u}$ is the mean density of the same invertebrate taxon within the unoccupied plots on that sampling date, and $S$ is the number of $P$. cinereus collected within the plots on that date. Interaction strengths were calculated for each taxon that was found to be significant responder to the presence of $P$. cinereus. Linear regression was used to characterize the relationship of interaction strength to leaf litter density and percentage of moisture. Because the sample points were not statistically independent, regression statistics are provided for heuristic evaluation of relationships, not formal hypothesis testing.

\section{RESUlts \\ Efficacy of ACO Treatments}

From 2003 through 2008, 215 P. cinereus were encountered within the study plots. The number of ACOs was the strongest predictor of number of salamanders observed among plots, and the probability of encountering one or more salamanders within plots increased with the number of ACOs (Fig. 1A; Table 1). The ordinal regression model that included only ACOs as a predictor of salamander numbers out-performed alternative models. $\mathrm{AIC}_{\mathrm{Cmin}}$ was associated with the "ACO only" model for nine of the 12 sampling periods, and the ACO effect was significant statistically for seven of the 12 sampling dates (Table 1), a result that is highly unlikely to occur by chance alone (Moran's $p_{\alpha=0.05}<0.001$ for $K$ $=7$ of $N=12$ tests). Of the alternative models, models that included the ACO effect were supported most strongly. However, the "ACO only" models were, on average, three times more likely than models including both ACO number and litter dry mass as predictors (mean evidence ratio $=3.18 \pm 0.31$ ) or models that included ACO number and 


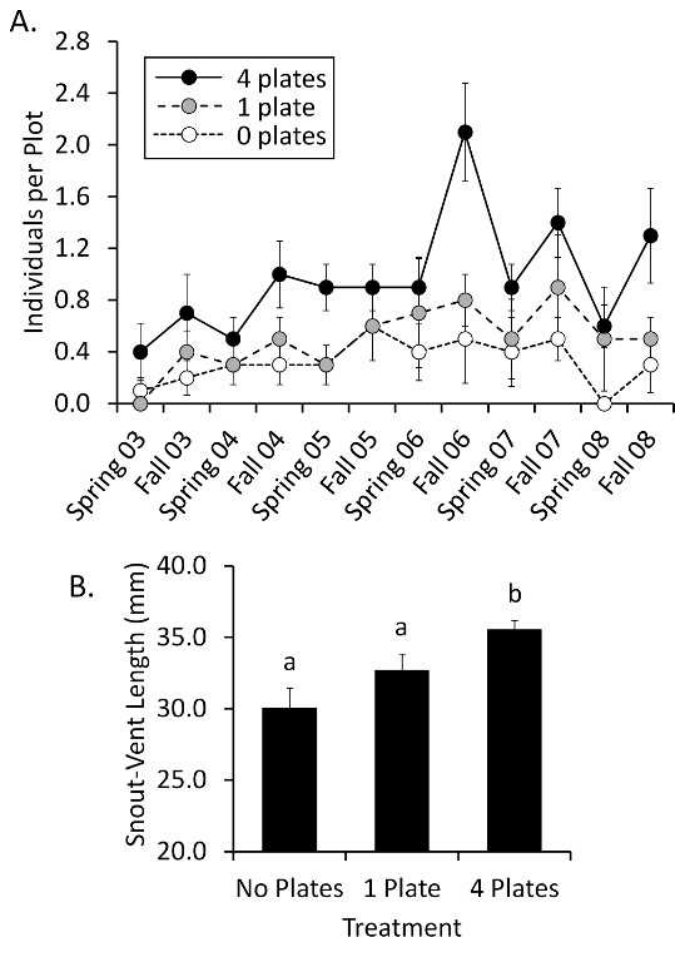

FIG. 1.-(A) Number of Plethodon cinereus captures per plot as a function of artificial cover treatment (ACOs) from spring 2003 through fall 2008. (B) Snout-vent lengths of $P$. cinereus as a function of ACO treatment. Means with different letters indicate a significant difference according to post-hoc means test (Tukey's honestly significant difference). Means in both figures are shown \pm one standard error of the mean.

percentage of litter moisture (mean evidence ratio $=2.74 \pm 0.39$ ). The "ACO only" model was nearly 10 -fold more likely than models that included all three predictors (mean evidence ratio $=9.69 \pm 2.03$ ). The "ACO only" models were $233.95 \pm 144.55$ times more likely than models that excluded the ACO effect and included litter dry mass and/ or percentage of litter moisture.

Surface densities of $P$. cinereus showed significant seasonal and interannual variation (Fig. 1A). Salamander densities were generally greater in fall than spring. Averaged across sampling dates and treatments, fall densities $\left(0.23 \pm 0.02 \mathrm{~m}^{-2}\right)$ were $64 \%$ greater than spring densities $\left(0.14 \pm 0.02 \mathrm{~m}^{-2}\right)$. In comparison to spring, the probabilities of encountering one or more salamanders within plots increased for all three ACO categories in
Table 1.-Results of "ACO only" ordinal logistic regression models predicting number of salamanders per plot for each sampling period, 2003-2008.

\begin{tabular}{ccccc}
\hline & & \multicolumn{3}{c}{ Predicted probabilities $^{\mathrm{B}}$} \\
\cline { 3 - 5 } & ACO effect $^{\mathrm{A}}$ & 0 & 1 & 4 \\
\hline Spring & & & & \\
2003 & $0.54 \pm 0.34(0.09)$ & 0.04 & 0.07 & 0.29 \\
2004 & $0.23 \pm 0.22(0.30)$ & 0.28 & 0.33 & 0.49 \\
2005 & $\mathbf{0 . 6 3} \pm \mathbf{0 . 2 5}(\mathbf{0 . 0 1})$ & $\mathbf{0 . 2 4}$ & $\mathbf{0 . 3 7}$ & $\mathbf{0 . 8 0}$ \\
2006 & $0.35 \pm 0.21(0.09)$ & 0.29 & 0.36 & 0.62 \\
2007 & $\mathbf{0 . 4 7} \pm \mathbf{0 . 2 2}(\mathbf{0 . 0 3})$ & $\mathbf{0 . 2 3}$ & $\mathbf{0 . 3 2}$ & $\mathbf{0 . 6 6}$ \\
2008 & $\mathbf{0 . 7 4} \pm \mathbf{0 . 2 9}(\mathbf{0 . 0 0 4})$ & $\mathbf{0 . 0 6}$ & $\mathbf{0 . 1 3}$ & $\mathbf{0 . 5 7}$ \\
& & & & \\
Fall & & & & \\
2003 & $0.32 \pm 0.26(0.16)$ & 0.25 & 0.31 & 0.54 \\
2004 & $\mathbf{0 . 5 2} \pm \mathbf{0 . 2 4}(\mathbf{0 . 0 2})$ & $\mathbf{0 . 3 2}$ & $\mathbf{0 . 4 4}$ & $\mathbf{0 . 7 9}$ \\
2005 & $0.26 \pm 0.20(0.20)$ & 0.42 & 0.48 & 0.66 \\
2006 & $\mathbf{0 . 8 9} \pm \mathbf{0 . 2 6}(<\mathbf{0 . 0 0 1})$ & $\mathbf{0 . 3 3}$ & $\mathbf{0 . 5 5}$ & $\mathbf{0 . 9 5}$ \\
2007 & $\mathbf{0 . 5 2} \pm \mathbf{0 . 2 2}(\mathbf{0 . 0 1})$ & $\mathbf{0 . 4 5}$ & $\mathbf{0 . 5 8}$ & $\mathbf{0 . 8 7}$ \\
2008 & $\mathbf{0 . 5 7} \pm \mathbf{0 . 2 3}(\mathbf{0 . 0 1})$ & $\mathbf{0 . 2 6}$ & $\mathbf{0 . 3 9}$ & $\mathbf{0 . 7 9}$ \\
\hline
\end{tabular}

${ }^{\mathrm{A}}$ Regression coefficients for $\mathrm{ACO} \pm$ standard error; $P$-value in parentheses based on likelihood ratio (statistically significant results are shown in bold).

${ }^{B}$ Estimated probabilities of finding one or more Plethodon cinereus within plots with 0,1 , or 4 ACOs.

fall (Table 1). Interannual variation was largely associated with increasing salamander densities from 2003 through 2006. Total salamander density, summed over all treatments, increased 12 -fold from a minimum of $0.05 \pm 0.03 \mathrm{~m}^{-2}$ in spring 2003 to a peak of $0.36 \pm 0.07 \mathrm{~m}^{-2}$ in fall 2006. Salamander density achieved an experiment-wise maximum of $0.67 \pm 0.12 \mathrm{~m}^{-2}$ in fall 2006 within the four ACO treatments.

SVL increased with the number of ACOs within plots (Fig. $1 B ; F_{2,214}=5.49, P=0.005$ ). Mean SVL of salamanders in the one-ACO and four-ACO plots exceeded $30 \mathrm{~mm}$, the minimum SVL of adult $P$. cinereus, indicating that plots with ACOs were largely occupied by adult territory holders.

\section{Interannual and Seasonal Variation in Litter Supply and Moisture Content}

ACO treatment had no effect on either dry mass of leaf litter $\left(F_{2,27}=1.06, P=0.36\right)$ or litter moisture $\left(F_{2,27}=1.03, P=0.81\right)$. However, leaf litter dry mass varied significantly among years and seasons (season $\times$ year interaction, Pillai's trace $=0.56, F_{5,23}=5.74, P$ $=0.001$; Fig. 2). On average, litter dry mass was two-fold greater in spring (454.20 \pm $\left.13.63 \mathrm{~g} \cdot \mathrm{m}^{-2}\right)$ than in fall $(227.50 \pm 8.17 \mathrm{~g} \cdot$ 

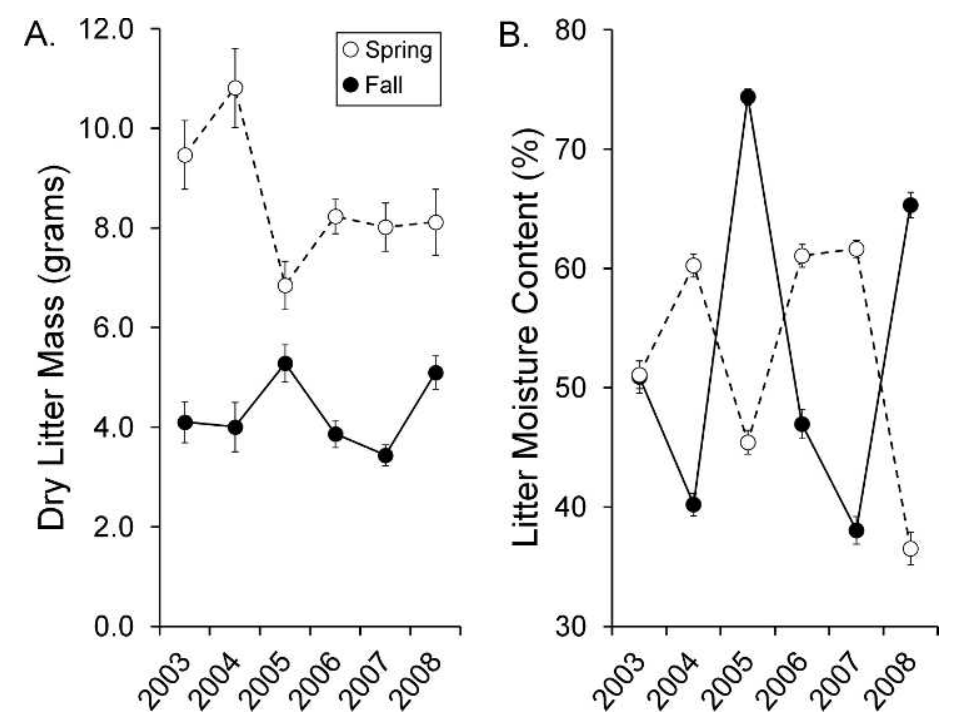

FIG. 2.-Dry mass (A) and moisture content (B) of leaf litter for spring and fall sampling periods from 2003 through 2008. Means are shown \pm one standard error of the mean.

$\left.\mathrm{m}^{-2}\right)$. Litter moisture (\%) varied among years and seasons, although an apparent reciprocal, presumably coincidental, pattern of wet and dry seasons produced an interaction between season and year ( season $\times$ year, Pillai's trace $=$ $\left.0.98, F_{5,23}=290.13, P<0.001\right)$. In several years $(2004,2006$, and 2007), wet spring samples were followed by much drier fall samples, whereas wet fall samples in 2005 and 2008 followed much drier spring samples (Fig. 2 ).

\section{Analyses of Invertebrate Density}

During the $6 \mathrm{yr}$ of the study, 23,964 invertebrates from 55 taxonomic categories were identified and counted. Total invertebrate density, summed across taxa, was generally higher in spring than fall in 2003 and 2004, but was greater in fall than spring from 2005 through 2008 and increased to an experiment-wise maximum for both seasons in 2007 (Fig. 3; year $\times$ season interaction, Pillai's trace $\left.=0.80, F_{5,23}=18.43, P<0.001\right)$. Invertebrate density, summed over all taxa, did not differ among ACO treatments $\left(F_{2,27}=\right.$ $1.94, P=0.16)$, and ACO treatments showed no significant two-way $($ ACO $\times$ season, Pillai's trace $=0.002, F_{2,27}=0.020, P=0.98 ; \mathrm{ACO} \times$ year, Pillai's trace $=0.33, F_{10,48}=0.95, P=$ 0.49 ) or three-way interactions with season and year (Pillai's trace $=0.29, F_{10,48}=0.82, P$ $=0.62$ ). Similarly, invertebrate species composition, as characterized by the five principal components (described in the following section) was not related to ACO treatments. Doubly multivariate RANOVA of the principal components found no between-subjects effect of ACOs (Pillai's trace $=0.45, F_{10,48}=$ $1.41, P=0.21)$ or within-subjects effects involving ACOs $(\mathrm{ACO} \times$ year, Pillai's trace $=$ $0.35, F_{50,675}=1.02, P=0.44$; ACO $\times$ season, Pillai's trace $=0.51, F_{10,48}=1.64, P=0.12$; ACO $\times$ season $\times$ year, Pillai's trace $=0.311$, $F_{50,675}=0.894, P=0.681$ ). Because ACOs did not introduce significant bias among plots in leaf litter mass, moisture, or invertebrate densities, subsequent analyses of invertebrate densities compared plots according to salamander occupancy, occupied vs. unoccupied plots, and omit ACOs as a treatment effect.

\section{Effects of Salamanders on Invertebrate Densities}

Analyses of salamander occupancy effects were initiated with taxa representing at least $0.5 \%$ of total abundance (Supplementary Appendix). These taxa were further reduced to five principal components with eigenvalues $\geq 1$, which accounted in combination for $58.02 \%$ of total variance in litter invertebrate 


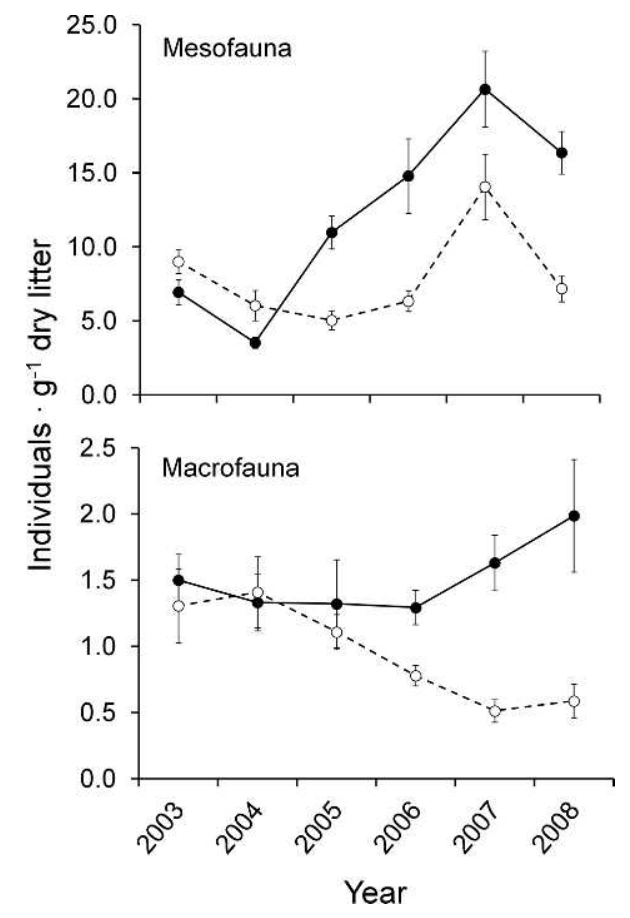

FIG. 3.-Density (individuals.g ${ }^{-1}$ dry litter) of mesofauna $(\approx 0.1-2 \mathrm{~mm}$ body length) and macrofauna $(>2$ $\mathrm{mm}$ ) for spring and fall sampling periods from 2003 through 2008. Means are shown \pm one standard error of the mean. Symbols are coded as in Fig. 2.

abundance. The first principal component (PC1) accounted for $24.42 \%$ of variance and was associated most strongly with oribatid mites $(r=0.79, P<0.001)$, hypogasturid Collembola $(r=0.69, P<0.001)$, Diptera larvae $(r=0.63, P<0.001)$, and onychiurid Collembola $(r=0.55, P<0.001)$. The second principal component (PC2) accounted for $10.92 \%$ of variance and was associated most strongly with entomobryid/tomocerid Collembola $(r=0.77, P<0.001)$, enchytraeid worms $(r=0.67, P<0.001)$, gamasid mites $(r=0.62$, $P<0.001)$, and julid millipedes $(r=0.54, P<$ $0.001)$. The third principal component (PC3) accounted for $8.03 \%$ of variance and was associated with Coleoptera larvae $(r=0.65, P$ $<0.001)$, pseudoscorpions $(r=0.64, P<$ $0.001)$, and isotomid Collembola $(r=0.63, P$ $<0.001)$. The fourth principal component (PC4), $7.63 \%$ of total variance, was an axis describing density of psocids $(r=0.78, P<$ $0.001)$ and Symphypleona Collembola $(r=$
$0.65, P<0.001)$. The fifth principal component (PC5), $7.03 \%$ of total variance, described a contrast between density of ants $(r=-0.72$, $P<0.001)$ and wandering, i.e., non-webbuilding, spiders (e.g., clubionid, gnaphosid, or lycosid spiders; $r=0.58, P<0.001$ ).

Occupancy of plots by $P$. cinereus exerted a statistically significant omnibus effect on invertebrate community composition, but the strength and direction of salamander effects varied seasonally, as indicated by a significant occupancy $\times$ season interaction (Pillai's trace $=0.06, F_{5,300}=3.99, P=0.002$ ). Four of five principal components showed significant responses to salamander occupancy (Table 2), a result unlikely by chance alone (Moran's $p_{\alpha=}$ $0.05<0.003$ for four of five tests). PC2 was the only component that showed no effect of salamander occupancy. With the exclusion of PC2, 11 invertebrate taxa remained for evaluation with univariate ANCOVAs; statistically significant effects of salamander occupancy were found for seven of the 11 taxa (Moran's $p_{\alpha=0.05}<0.01$ ).

The interaction of seasonal variation and salamander occupancy was exemplified most strongly by PC4, which showed generally lower or similar values on salamander-occupied plots in comparison to unoccupied plots in the spring, but showed higher values on salamander-occupied plots in the fall (Fig. 4). The two taxa loading most strongly onto PC4, the Symphypleona and psocids, both showed significant occupancy $\times$ season interactions (Fig. 5; Symphypleona, $F_{1,334}=9.71, P=$ 0.002 ; Psocidae, $\left.F_{1,334}=4.41, P=0.04\right)$. In spring samples, densities of Symphypleona were generally low, but were $55.4 \%$ lower on salamander-occupied plots than unoccupied plots (unoccupied, $0.12 \pm 0.03 \mathrm{~g}^{-1}$ dry litter; occupied, $0.07 \pm 0.02 \mathrm{~g}^{-1}$ dry litter). In the fall, Symphypleona densities were high and over two-fold greater on occupied (1.04 \pm $0.13 \mathrm{~g}^{-1}$ dry litter $)$ than unoccupied plots $(0.50$ $\pm 0.06 \mathrm{~g}^{-1}$ dry litter). Average psocid fall density within occupied plots $\left(0.31 \pm 0.07 \mathrm{~g}^{-1}\right.$ dry litter) was more than two-fold greater than density within unoccupied plots $(0.14 \pm 0.04$ $\mathrm{g}^{-1}$ dry litter). Psocid densities were low in the spring and similar on occupied and unoccupied plots $\left(0.02 \pm 0.04 \mathrm{~g}^{-1}\right.$ dry litter $)$. 


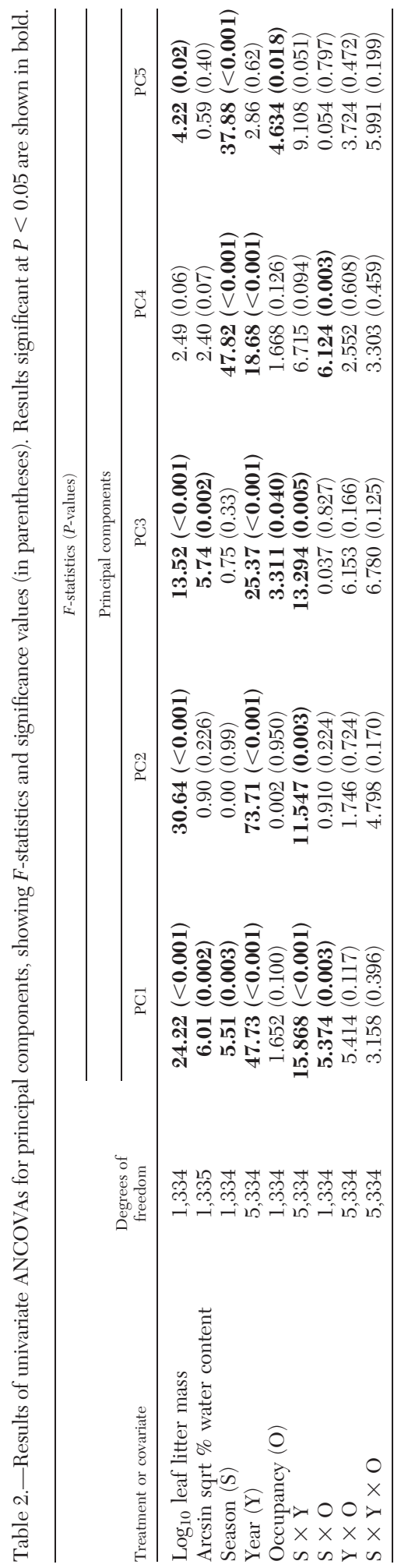

PC1 also showed significant seasonal variability in salamander effects (Table 2; Fig. 4). PCl was generally higher on unoccupied plots during the first $2 \mathrm{yr}$ of the study, but thereafter was generally greater on occupied plots in the fall (Fig. 4 ). This profile was most closely matched by hypogasturid Collembola, which loaded strongly on PCl (Fig. 5; occupancy $\times$ season, $F_{1,334}=4.20, P=0.04$ ). Oribatid mites, another PC1 taxon, also showed a significant occupancy $\times$ season interaction $\left(F_{1,334}=\right.$ $4.70, P=0.03)$, but several reversals in polarity of density between occupied vs. unoccupied plots produced a marginal three-way interaction (Fig. 5; occupancy $\times$ season $\times$ year, $\left.F_{5,334}=1.98, P=0.08\right)$. Similarly, reversals in density between occupied and unoccupied plots produced a three-way interaction for the onychiurid Collembola (Fig. 5; $F_{5,334}=3.06, P=0.01$ ), another taxon loading strongly on PC1.

PC3 was generally greater for plots occupied by $P$. cinereus, and seasonality was less apparent for this component (Fig. 4). The temporal profile of pseudoscorpion density (Fig. 5) was largely similar to that of PC3. Averaged over the entire experiment, the mean density of pseudoscorpions was approximately two-fold greater on occupied plots $\left(0.11 \pm 0.02 \mathrm{~g}^{-1}\right.$ dry litter $)$ in comparison to plots without salamanders $\left(0.05 \pm 0.01 \mathrm{~g}^{-1}\right.$ dry litter). However, pseudoscorpion densities became more variable during the last $2 \mathrm{yr}$ of observation. In 2007 and fall 2008, pseudoscorpions were more abundant in unoccupied plots. These reversals of polarity resulted in a significant three-way interaction of occupancy, season, and year for pseudoscorpions $\left(F_{5,334}=2.61, P=0.03\right)$. There were also periods when isotomid Collembola, another taxon loading strongly on PC3, was especially abundant on salamander-occupied plots (e.g., 2005 and fall 2008; Fig. 5). Averaged over the entire experiment, mean densities of isotomids were $13 \%$ greater on plots with $P$. cinereus $\left(0.96 \pm 0.10 \mathrm{~g}^{-1}\right.$ dry litter $)$ than plots lacking salamanders $\left(0.85 \pm 0.09 \mathrm{~g}^{-1}\right.$ dry litter). However, isotomids also showed several sampling periods when densities were similar on occupied and unoccupied plots, as well as one period, spring 2007, when 


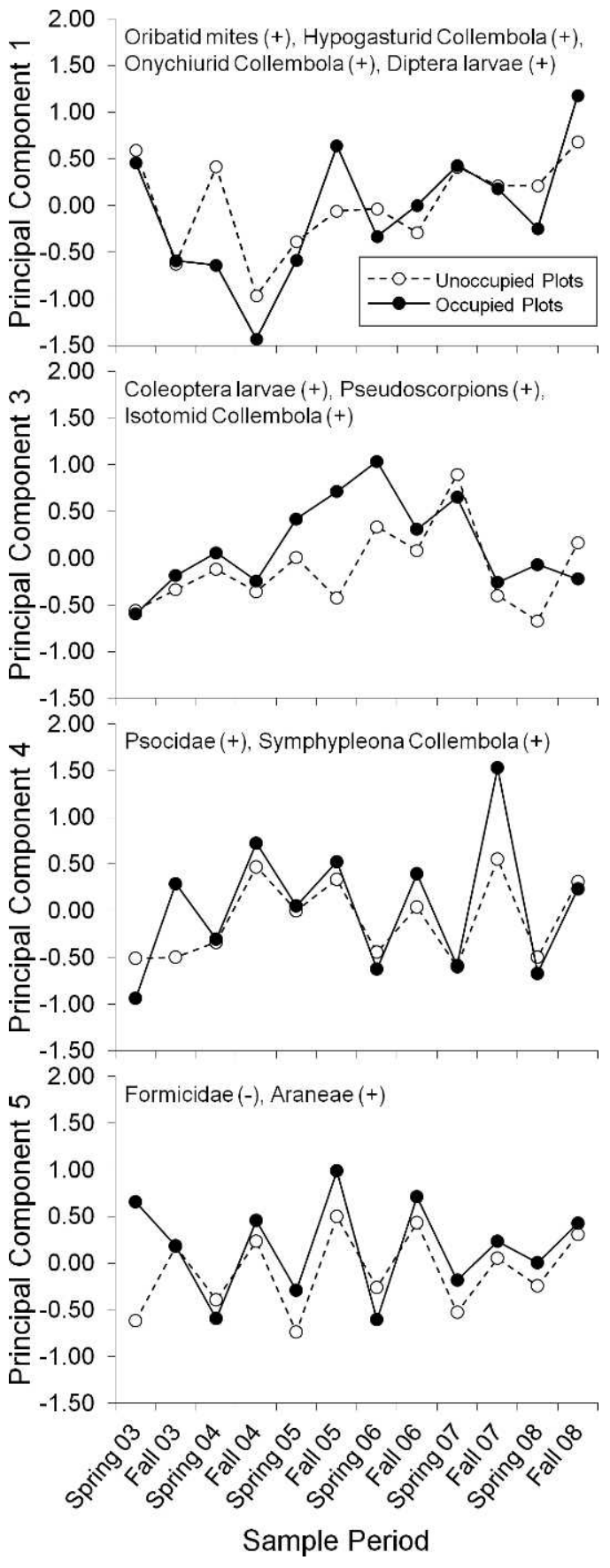

FIG. 4.-Plots of principal components as functions of sample period and salamander plot occupancy. Plots are annotated to indicate taxa loading strongly on principal components and polarity of the association $(+$ or -$)$ between each taxon and its component. isotomid densities were considerably greater on unoccupied plots (Fig. 5). This variability for isotomids generated a marginally significant interaction between season and occupancy for this taxon $\left(F_{1,334}=3.31, P=0.07\right)$.

PC5 also tended to be greater on salamanderoccupied plots than plots not occupied by salamanders (Fig. $4 ; F_{1,334}=4.63, P=0.02$ ). PC5 was largely influenced by contrasting seasonal patterns of density for ants and wandering spiders. Densities of spiders and ants were similar when averaged over the entire experiment (spiders, $0.09 \pm 0.01 \mathrm{~g}^{-1}$ dry litter; ants, $0.08 \pm 0.03 \mathrm{~g}^{-1}$ dry litter). However, ant densities were high in spring samples $(0.16 \pm$ $0.06 \mathrm{~g}^{-1}$ dry litter) when spiders were few $(0.03$ $\pm 0.01 \mathrm{~g}^{-1}$ dry litter), whereas spiders were more abundant in fall $\left(0.14 \pm 0.03 \mathrm{~g}^{-1}\right.$ dry litter) when ant densities were low (0.01 \pm $0.003 \mathrm{~g}^{-1}$ dry litter). Singly, neither taxon showed a strong effect of salamander occupancy. However, P. cinereus exerted a positive effect on spider density that showed marginal statistical significance $\left(F_{1,334}=3.309, P=0.08\right)$. Apparently, the effect on spiders, coupled with a slight, but not statistically significant, trend of decreased ant densities in salamander-occupied plots $\left(F_{1,334}=2.45, P=0.12\right)$, generated a statistically significant combinatorial effect of salamander occupancy on PC5.

\section{Effects of Litter Mass and Moisture on Salamander Effects}

Per capita interaction strength was related to seasonal and interannual variation in litter mass for five taxa, and for three of those taxa, litter moisture was also a predictor of interaction strength (Fig. 6). Interaction strength declined with increasing leaf litter mass among the Symphypleona Collembola, hypogasturid Collembola, isotomid Collembola, and oribatid mites (Table 3; Fig. 6). The effect of salamanders on onychiurid Collembola showed a quadratic response with the highest value at intermediate litter mass (Table 2; Fig. 6). Increased litter moisture was associated with increasing interaction strength for the Symphypleona, hypogasturid, and isotomid Collembola (Table 3; Fig. 6). Salamander effects on oribatid mites and onychiurid Collembola did not vary with litter moisture. Variation in interaction strengths for 


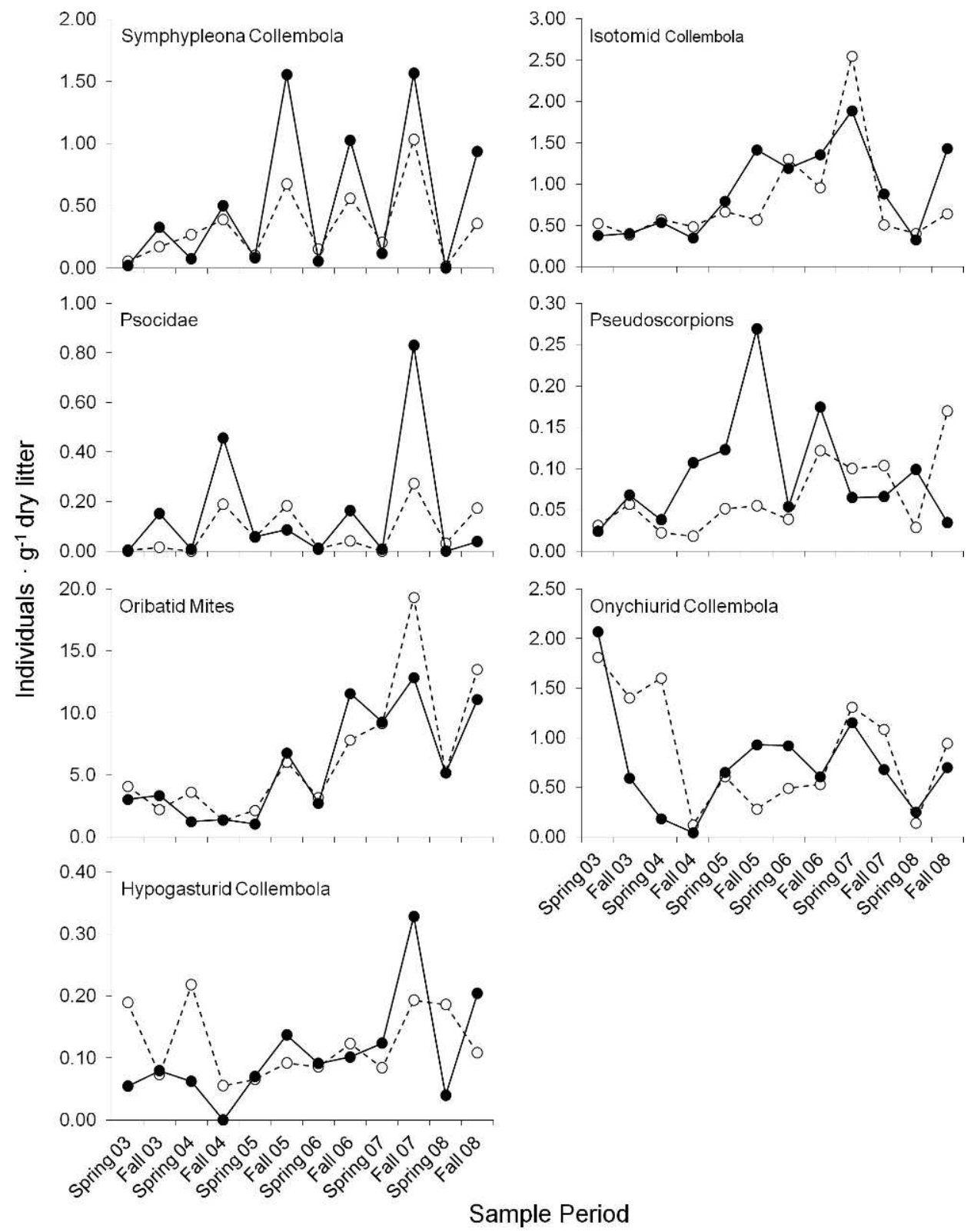

FIG. 5.-Density profiles (individuals $\cdot \mathrm{g}^{-1}$ dry litter) for taxa responding to salamander plot occupancy for spring and fall sampling periods from 2003 through 2008. Symbols and lines are coded as in Fig. 4.

psocids and pseudoscorpions was not related to litter mass or moisture.

\section{Discussion}

I found that the density and species composition of forest floor invertebrates differed between unrestricted, open plots occupied by the terrestrial salamander, $P$. cinereus, and plots not occupied by salamanders. Moreover, the invertebrates affected by $P$. cinereus were among the most abundant mesofauna taxa and included groups known to have important effects on decomposition and 

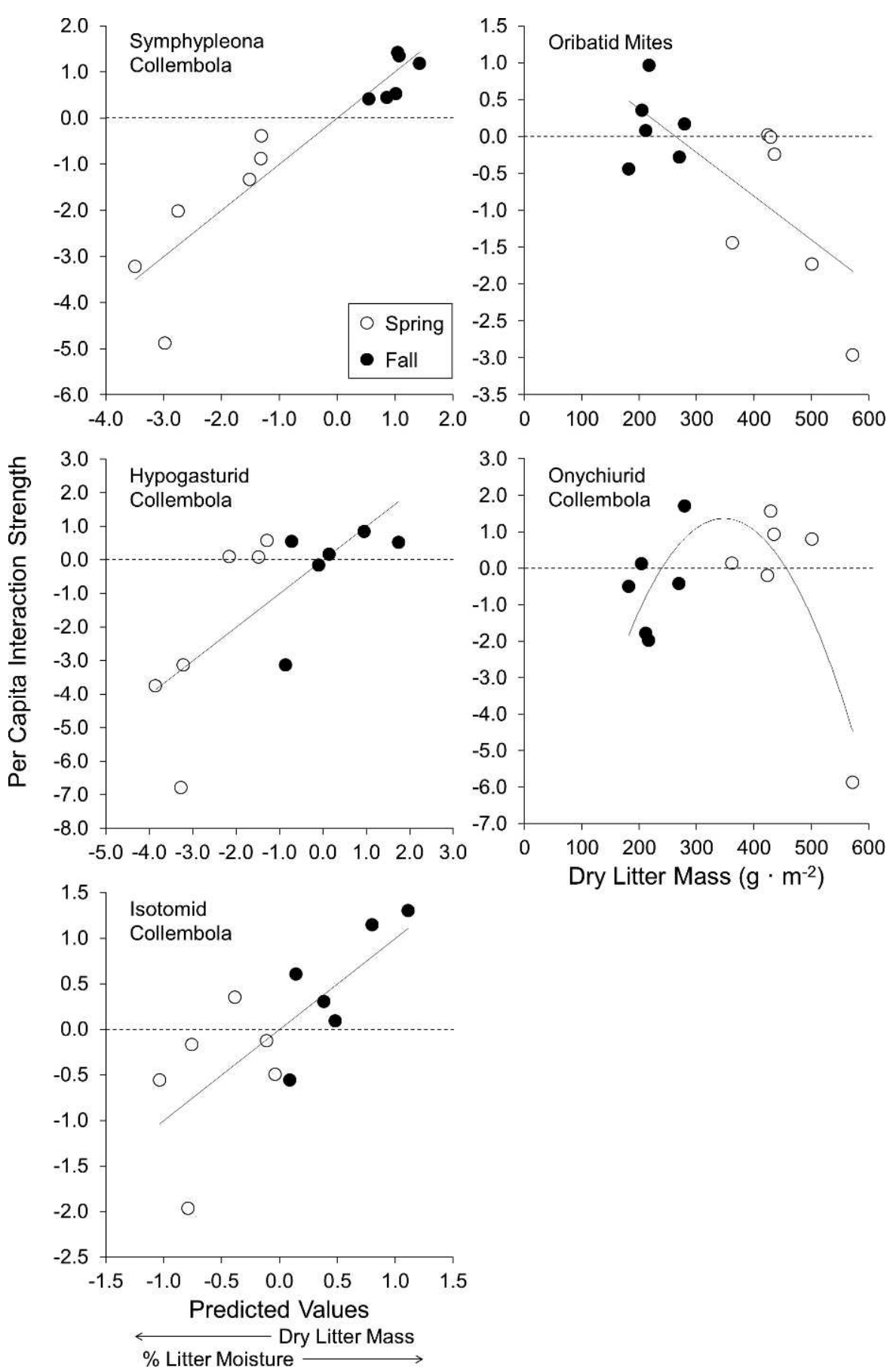

FIG. 6.-Plots of per capita interaction strengths as functions of dry mass of leaf litter $\left(\mathrm{g} \cdot \mathrm{m}^{-2}\right)$ and litter moisture (\%) for spring and fall sampling periods. For taxa responding to both litter mass and moisture (i.e., Symphypleona, Hypogasturidae, Isotomidae), interaction strengths are plotted as a function of predicted values derived from multiple linear regressions (Table 3). 
Table 3.- Regression statistics relating per-capita interaction strengths to litter dry mass and percentage of litter moisture. Regression coefficients are shown with standard errors in parentheses. Significance of regressions are shown, but may be biased by nonindependence among sampling periods.

\begin{tabular}{lcrrrrr}
\hline & & \multicolumn{5}{c}{ Regression coefficients } \\
\cline { 3 - 6 } Taxon & $R^{2}$ & \multicolumn{1}{c}{ Y-intercept } & Litter mass $\left(\mathrm{g} \cdot \mathrm{m}^{-2}\right)$ & Litter moisture (\%) & Litter mass $^{2}$ & $P$-value \\
\hline Symphypleona Collembola & 0.86 & $1.380(0.180)$ & $0.010(0.002)$ & $5.394(2.127)$ & - & $<0.001$ \\
Hypogasturid Collembola & 0.51 & $-2.328(2.708)$ & $-0.012(0.004)$ & $10.014(4.890)$ & - & 0.040 \\
Isotomid Collembola & 0.56 & $-0.513(0.921)$ & $-0.005(0.002)$ & $3.876(0.662)$ & - & 0.024 \\
Onychiurid Collembola & 0.62 & $-12.682(3.785)$ & $0.081(0.023)$ & - & $-1.16 \times 10^{-4}$ & 0.014 \\
& & & & $\left.-0.15 \times 10^{-5}\right)$ & 0.008 \\
Oribatid mites & 0.52 & $1.553(0.656)$ & $-0.006(0.002)$ & - & - & \\
\hline
\end{tabular}

nutrient cycling within the forest floor (e.g., oribatid mites and Collembolal; Swift et al., 1979; Seastedt, 1984; Moore et al., 1988). Hence, my findings support the hypothesized top-down, regulatory role for plethodontid salamanders within the terrestrial detrital food web (Burton and Likens, 1975a,b; Hairston, 1987; Davic and Welsh, 2004). However, salamander effects on invertebrate densities varied in both magnitude and direction among taxa, as well as within taxa among seasons and years. Plethodon cinereus was associated with negative, positive, and no effects on invertebrate densities, reflecting essentially the full range of salamander-mediated dynamics observed in earlier studies within enclosures or microcosms (Wyman, 1998; Rooney et al., 2000; Walton and Steckler, 2005; Walton et al., 2006; Homyack et al., 2010).

A notable aspect of the dynamics reported here was the strongly seasonal variation in the strength and direction of salamander-mediated effects for several taxa (Fig. 6). Seasonal as well as interannual variability in salamander effects were related to variation in litter amount and, to a lesser extent, litter moisture. In part, these effects can be interpreted as the result of microclimatic constraints on the surface activity of $P$. cinereus and litter invertebrates. The behavior of $P$. cinereus is strongly constrained by thermal and hydric conditions (Heatwole, 1962; Spotila, 1972; Feder, 1983; Keen, 1984; Grover, 1998). Surface densities of $P$. cinereus are greater, and individuals forage longer and farther, and consume more prey during relatively cool, moist conditions when the risk of desiccation is low, whereas $P$. cinereus consume fewer, often smaller, prey when confined to cover objects or fossorial habitats during warm, dry periods (Jaeger, 1972, 1980a,b, 1990; Feder, 1983). From this perspective, the negative effects of $P$. cinereus on invertebrate densities may reflect periods when microclimatic conditions were favorable for salamander foraging (Walton, 2005). The negative effects of salamander occupancy were especially prominent in the spring, when the litter layer was thick. Thick litter retains moisture and buffers $P$. cinereus and litter invertebrates from desiccation (Seastedt and Crossley, 1981; Ash, 1995, 1997). For several taxa, the strongest negative effects of $P$. cinereus observed in the current study occurred in spring 2004 when litter mass achieved the experiment-wise maximum $\left(572.26 \pm 42.00 \mathrm{~g}\right.$ dry litter $\left.\cdot \mathrm{m}^{-2}\right)$ and the leaf litter was relatively moist $(60.26 \pm 0.97 \%$ moisture content).

In contrast, the same taxa that exhibited negative responses to $P$. cinereus in the spring often showed positive responses to $P$. cinereus when litter mass was low, especially in the fall (Fig. 6). Microclimatic constraint could be at work here as well, presuming the risk of desiccation was greater when the litter layer was thin, and, thereby, suppressed salamander foraging activity. Although surface densities of $P$. cinereus were greater in fall than spring (Fig. 1A), perhaps the salamanders were largely confined to cover objects when the litter layer was thin, thereby reducing predation pressure on invertebrates in the surrounding litter. However, microclimatic constraint seems an inadequate explanation in this case. If thin litter in the fall constrained salamander foraging, invertebrate densities within plots occupied by salamanders would be expected to be similar to invertebrate densities within unoccupied plots, not greater, as was observed here. Moreover, desiccation 
seems unlikely to have been a constraint in fall 2005 or fall 2008, sampling periods during which the positive effects of $P$. cinereus on invertebrate densities were greatest. Notably, these two periods were associated with the two highest values of litter moisture recorded during the experiment, as well as the highest leaf litter masses recorded among the fall samples (Fig. 2B). Hence, the strongest positive salamander effects were produced during periods that were also likely to have been permissive of salamander surface activity.

What then accounts for the change of polarity of salamander effects from spring to fall, or between a thick and thin leaf litter layer? One possibility is that $P$. cinereus and some mesofaunal taxa share similar requirements for features of the microhabitat, i.e., patches that have both adequate cover and litter thick enough to effectively retain moisture and buffer against temperature extremes. As litter thickness declines, perhaps such patches become limited in supply. At least three findings, however, suggest that shared microhabitat requirements were, at best, a minor component of the dynamics reported here. First, no statistically significant differences in litter mass or moisture were detected between salamander-occupied and unoccupied plots. Second, the number of ACOs was the single predictor of salamander occupancy among plots, not litter mass or moisture. Third, ACOs were not a predictor of invertebrate community composition. Apparently, it was the presence of $P$. cinereus in plots with ACOs, not ACOs per se, to which mesofauna responded. Another alternative is that $P$. cinereus actively selected plots within which to establish territories based upon already existing high densities of prey. This was Gabor's (1995) interpretation of her observation that territories occupied by large $P$. cinereus contained higher densities of potential prey than the territories of smaller individuals. There may be especially strong motivation for male $P$. cinereus to establish territories within prey-rich patches, since female $P$. cinereus may assess the quantity or quality of prey resources within male territories by "squashing" and inspecting the contents of fecal pellets deposited by resident

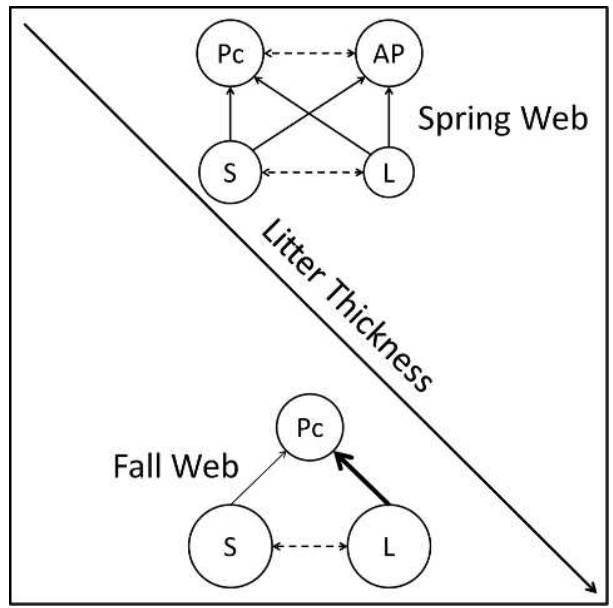

FIG. 7.-Hypothesized changes in interaction web modules within Plethodon cinereus territories (large box) with declining litter mass. In spring, $P$. cinereus $(\mathrm{Pc})$ and arthropod predators (AP) compete (dashed horizontal arrows) within thick litter layer for low density of small microbi-detritivore $(\mathrm{S})$ and large (L) detritivore prey. In early fall, thin litter promotes expulsion of arthropod predators from territory by $P$. cinereus, and high prey densities allow selective predation (thick arrow) on larger (L) prey types. Therefore, microbi-detritivores (S) experience less salamander predation (thin arrow) and less competition (horizontal dashed arrow) from large detritivores (L).

males (Walls et al., 1989; Jaeger and Wise, 1991; Karuzas et al., 2004). However, habitat selection based upon prey density also seems to be an incomplete explanation, since it cannot account for dynamics remarkably similar to those reported here that have been observed in earlier experiments within enclosures and microcosms (Rooney et al., 2000; Walton and Steckler, 2005; Walton et al., 2006). The results of those earlier studies suggest that the establishment of a territory by $P$. cinereus could, in fact, promote a localized increase in density of potential prey within salamander territories. From this perspective, findings such as Gabor's (1995) may have reflected the creation of spatial variation in invertebrate densities by $P$. cinereus, rather than a response of salamanders to existing variation (Walton and Steckler, 2005).

Rather, I suggest that the dynamics observed here may be explained by seasonal differences in leaf litter mass and the density and species composition of leaf litter fauna 
that resulted in interaction webs that differed between the spring and fall sampling periods (Fig. 7). Specifically, I suggest that variation in direction of top-down effects of $P$. cinereus were determined by (1) prey selection by $P$. cinereus and (2) variation in cost and effectiveness of territorial defense expressed within the contexts of seasonal differences in litter mass, abundance of preferred salamander prey, and interactions with arthropod predators that are intraguild competitors of the salamanders. I outline the evidence for these hypotheses below.

\section{Prey-Selection Hypothesis}

Plethodon cinereus select prey on the basis of size and nutrient quality, and become more selective as density of preferred (e.g., larger, prey increases; Jaeger and Barnard, 1981; Jaeger and Rubin, 1982). Further, P. cinereus actively forages on the forest floor seeking preferred prey of higher caloric content, i.e, larger, soft-bodied prey, when microclimatic conditions are favorable, whereas the salamanders remain under cover during warm, dry periods where they have access to fewer and smaller prey (Jaeger, 1980a,b, 1990; Jaeger et al., 1981, 1982). Perhaps variation in the strength and direction of $P$. cinereus effects observed here reflect prey-switching (sensu Murdoch, 1969) in which P. cinereus exert differential numerical effects on prey taxa depending upon access to and abundance of larger prey. By focusing predation on abundant, preferred prey, predators can promote increases among less preferred prey types (Holt and Lawton, 1994). In addition, selective predation may also influence the outcome of competition and predator-prey interactions among prey taxa (Holt and Lawton, 1994; Chase et al., 2002). Macrofaunal detritivores (e.g., millipedes and isopods, may compete with Collembola for detrital resources; Scheu, 2002); hence, salamander-mediated reductions of macrofauna should reduce competition and promote increased densities of Collembola (Walton et al., 2006). Indeed, dynamics consistent with these predictions have been observed in the microcosm and enclosure studies of $P$. cinereus. In several studies, salamander-mediated increases in mesofaunal microbi-detritivores, including taxa showing positive responses in the current study, were associated with negative effects upon macrofaunal detritivores and/or an intermediate predator (Rooney et al., 2000; Walton and Steckler, 2005; Walton et al., 2006). Further, the strength of positive, indirect effects on mesofauna apparently increase with the abundance of larger prey taxa, as would be predicted by the preyswitching hypothesis. Within litter containing high initial densities of isopods, millipedes, and pseudoscorpions, Walton et al. (2006) found that the presence of a single $P$. cinereus was associated with significant reductions of those taxa, but also a 12-fold increase in small Collembola compared to control microcosms without salamanders. In contrast, the presence of $P$. cinereus had a slightly negative effect on the same Collembola taxa within litter with low initial densities of isopods, millipedes, and pseudoscorpions.

Variation in the direction and magnitude of salamander-mediated effects reported here were also largely consistent with seasonal variation in the opportunity for $P$. cinereus to select larger prey. Densities of both mesofauna and macrofauna were generally higher in fall than spring (Fig. 3). Hence, positive salamander-mediated effects were most prevalent when $P$. cinereus would have had the greatest opportunity to select larger prey. Further, the exclusively negative effects of $P$. cinereus observed in the first $2 \mathrm{yr}$ of the study (Walton, 2005) also conformed to the expectations of prey-switching. From 2003 through 2004, prey densities were relatively low and similar in spring and fall, suggesting limited availability of alternative prey (Fig. 3). However, the positive effects of $P$. cinereus on mesofauna densities observed in the current study were not associated with reductions in larger invertebrates, as was observed in the microcosm studies. This discrepancy may have been a function of the litter sampling method employed here. Although Berlese extraction of randomized leaf litter samples is an effective method for quantitative sampling of mesofauna, this method typically underestimates densities of larger and more mobile invertebrates (Topping and Sunderland, 1992; Sabu et al., 2011) and is also likely to underestimate densities of invertebrates 
with clumped distributions on the forest floor e.g., aggregations of Fungus Gnat larvae (e.g., Sciaridae) in wet depression. Alternatively, salamander plots may have been replenished by movement of highly abundant, mobile organisms from adjacent patches on the forest floor, a dynamic that was not possible in the microcosm or field enclosure studies. The influx of highly abundant, preferred prey into salamander territories would be a strong stimulus prompting $P$. cinereus to divert its attention away from smaller prey.

\section{Intraguild-Territoriality Hypothesis}

Territorial behavior expressed by $P$. cinereus toward arthropod intraguild competitors, including spiders, centipedes, and carabid beetles, may have also contributed to the dynamics reported here. Specifically, the ability of $P$. cinereus to exclude intruders from their territories may decrease with increasing litter thickness. In turn, litter thickness could influence (1) the overall predation pressure exerted by the salamanders and arthropod predators within salamander territories and (2) the ability of $P$. cinereus to select preferred prey.

Plethodon cinereus establishes feeding territories, which they defend against intrusion from conspecifics (Mathis et al., 1995). In addition, $P$. cinereus also defends its territory against arthropod predators that are likely to compete with salamanders for food resources (e.g., centipedes, carabid beetles, and spiders; Gall et al., 2003; Hickerson et al., 2004; Anthony et al., 2007; Figura, 2007). In response to these arthropod intraguild competitors, or substrates imbued with their odors, $P$. cinereus exhibits the same aggressive behaviors used to expel conspecific intruders (Gall et al., 2003; Hickerson et al., 2004; Anthony et al., 2007; Figura, 2007). In the field, $P$. cinereus and the centipede Scolopocryptops sexspinosus only rarely occur under the same cover object (Hickerson et al., 2004). Further, during a 4-yr predator-removal experiment in replicated open plots, Hickerson et al. (2012) found that the abundance of spiders increased under ceramic-plate ACOs from which $P$. cinereus had been removed, and $P$. cinereus abundance in- creased under ACOs from which centipedes had been removed.

However, the likelihood of encounters between $P$. cinereus and arthropod competitors may increase with litter thickness. Thick, structurally complex leaf litter habitats promote accumulation of arthropod predators (Langelotto and Denno, 2004, 2006). For example, lycosid spiders accumulate within structurally complex litter habitats where they attain increased foraging success and experience less cannibalism and fewer encounters with intraguild predators (Denno et al., 2002; Langellotto and Denno, 2004, 2006; Schmidt and Rypstra, 2010). By allowing multiple arthropod predators to co-occur within the same location, structurally complex litter habitats enhance the strength of top-down regulation of lower trophic levels (Denno et al., 2002). Previous studies of leaf litter habitat complexity have focused exclusively on arthropod predators, but thick, structurally complex litter may have similar effects within $P$. cinereus territories. With greater volume of territorial space to patrol and multiple arthropod competitors with which to contend, the efficiency of territorial defense by $P$. cinereus may decline. From this perspective, arthropod predators would be more likely to co-occur within salamander territories with resident $P$. cinereus in spring when litter is thick and thereby increase overall predation pressure on mesofaunal prey (Fig. 7). Conversely, at lower litter volumes characteristic of the fall sampling periods, $P$. cinereus may be more effective at excluding intraguild predators from their territories (Fig. 7). In this case, the positive effects of salamanders on mesofauna could arise from two complementary forces: (1) the reduction of the number of arthropod predators within salamander-occupied plots and (2) increased predation pressure in unoccupied plots from the arthropod predators that were expelled from salamander territories. The positive effect of litter moisture on interaction strength observed for several mesofaunal taxa was also consistent with intraguild territoriality. Moist litter would permit longer surface activity for $P$. cinereus and, perhaps, more effective territorial defense. 
Interactions between $P$. cinereus and arthropod predators may also reinforce the effects of leaf litter thickness on prey selection by $P$. cinereus. As the costs of territorial defense increase with increasing litter thickness, $P$. cinereus may become less selective for larger prey. Jaeger et al. (1983) demonstrated that resident $P$. cinereus spend more time in aggressive display and biting, less time foraging, and become less selective of larger prey in response to cues indicating conspecific intruders into their territories. If territorial defense against arthropod predators incurs similar costs, then the ability of $P$. cinereus to select preferred prey is expected to decline as litter thickness and competition from arthropod predators increase.

In summary, I propose that the top-down effects of $P$. cinereus within the forest floor were determined by behavioral responses of salamanders to the abundance of prey and competitors within its territory, as mediated by the bottom-up effects of leaf litter mass and litter moisture. I suggest that the relatively cool, moist conditions in both spring and fall enabled prolonged surface activity by $P$. cinereus, but seasonal differences in litter thickness and prey abundance produced very different interaction webs in spring and fall (Fig. 7). In the spring, salamander-mediated effects were played out in an environment in which invertebrate densities were generally low. Hence, if salamanders and predatory arthropods competed for a low prey resource, they did so within a thick, structurally complex litter layer that promoted co-occurrence of arthropod predators within salamander territories. In such conditions, the ability of $P$. cinereus to select larger, alternative prey may have been compromised by both low availability of alternative prey and increased investment into territorial defense. The combined effects of these factors should enhance the strength of predation upon mesofauna exerted by both salamander and arthropod predators. However, by the time of the fall samples, invertebrate densities had increased within the litter through emergence and reproduction, while decomposition had reduced litter thickness. A thinner litter layer may have permitted salamanders to achieve more effective territorial defense against both intraspecific and arthropod competitors. In addition, higher densities of invertebrates may have afforded $P$. cinereus more opportunities to select larger prey. Hence, in the fall, increased densities of mesofauna within salamander territories may have been generated through reduced predation by both salamanders and arthropod predators, and through lesser competition from larger detritivores that were the focus of salamander predation. Of course, the mechanisms proposed here rest upon a number of untested hypotheses, especially the relationships among litter thickness, prey selection, and territorial defense by $P$. cinereus. Fortunately, these are relationships that should be amenable to experimental manipulation. Of particular interest would be comparisons of salamander effects and food web structure along experimental gradients of litter thickness and moisture (Hickerson et al., 2012).

The results of this study also suggest that terrestrial plethodontid salamanders may be well positioned to stabilize forest ecosystem processes. Generalist predators may impart stability to food webs through spatial and temporal variation in utilization of multiple trophic channels that differ in rates of energy processing and biomass turnover (McCann et al., 2005; Rooney et al., 2008). By responding to differences in prey density among channels through prey-switching, predators dampen oscillations in prey densities and, thereby, energy flow among channels (McCann et al., 2005). The detrital food web of the forest floor is compartmentalized into trophic channels of primary and secondary decomposers consuming leaf litter and microbial (principally fungal) resources, respectively. Roughly defined by macrofaunal (primary decomposers) and mesofaunal (secondary decomposers) taxa, the two channels interact to have important effects on decomposition rate and nutrient cycling (Scheu, 2002; Pollierer et al., 2009). As a selective predator, P. cinereus couples these two compartments (Fig. 7) and provides a mechanism for dampening variation in invertebrate density and, potentially, energy and nutrient flows between them.

Acknowledgments.-I thank L. Petit and the natural resources staff of the Cuyahoga Valley National Park for access to the field site and for use of the Woodlake 
Environmental Field Station. I also thank G. Varhegyi, N. Mikash, A. Rogers, K. Freeman, and Z. Walton for their assistance in the field. This work was conducted under National Park Service scientific research permits (CUVA2001-SCI-0006 and CUVA-2004-0007), and protocols approved by the Cleveland State University Institutional Animal Care and Use Committee (21104-WAL-AS).

\section{Literature Cited}

Anthony, C.D., C.M. Hickerson, and M.D. Venesky. 2007. Responses of juvenile terrestrial salamanders to introduced (Lithobius forficatus) and native centipedes (Scolopocryptops sexspinosus). Journal of Zoology 271:54-62.

Ash, A.N. 1995. Effects of clear-cutting on litter parameters in the southern Blue Ridge Mountains. Castanea 60:89-97.

Ash, A.N. 1997. Disappearance and return of plethodontid salamanders to clearcut plots in the southern Blue Ridge Mountains. Conservation Biology 11:983-989.

Burnham, K.P., and D.R. Anderson. 2002. Model Selection and Multimodel Inference: A Practical Information-Theoretical Approach. Springer-Verlag, USA.

Burton, T.M., and G.E. Likens. 1975a. Salamander populations and biomass in the Hubbard Brook Experimental Forest, New Hampshire. Copeia 1975:541-546.

Burton, T.M., and G.E. Likens. 1975b. Energy flow and nutrient cycling in salamander populations in the Hubbard Brook Experimental Forest, New Hampshire. Ecology 56:1068-1080.

Chase, J.M., P.A. Abrams, J.P. Grover, S. Diehl, P. Chesson, R.D. Holt, S.A. Richards, R.M. Nisbet, and T.J. Case. 2002. The interaction between predation and competition: a review and synthesis. Ecology Letters 5:302-315

Davic, R.D., and H.H. Welsh, Jr. 2004. On the ecological role of salamanders. Annual Review of Ecology, Evolution, and Systematics 35:405-434.

Denno, R.F., C. Gratton, M.A. Peterson, G.A. Langellotto, D.L. Finke, and A.F. Huberty. 2002. Bottom-up forces mediate natural enemy impact in a phytophagous insect community. Ecology 83:1443-1458.

Feder, M.E. 1983. Integrating the ecology and physiology of plethodontid salamanders. Herpetologica 39:291310 .

Figura, A. 2007. Behavioral interactions between RedBacked Salamanders (Plethodon cinereus) and adult Amaurobiid spiders (Wadotes). M.S. Thesis, John Carroll University, USA.

Gabor, C.R. 1995. Correlational test of Mathis' hypothesis that bigger salamanders have better territories. Copeia 1995:729-735.

Gall, S.B., C.D. Anthony, and J.A. Wicknick. 2003. Do behavioral interactions between salamanders and beetles indicate guild relationship? American Midland Naturalist 149:363-374.

Grover, M.C. 1998. Influence of cover and moisture on abundances of the terrestrial salamanders Plethodon cinereus and Plethodon glutinosus. Journal of Herpetology 32:489-497.
Hairston, N.G., Sr. 1987. Community Ecology and Salamander Guilds. Cambridge University Press, USA.

Heatwole, H. 1962. Environmental factors influencing local distribution and activity of the salamander, Plethodon cinereus. Ecology 43:460-472.

Hickerson, C.A., C.D. Anthony, and J.A. Wicknick. 2004. Behavioral interactions between salamanders and centipedes: competition in divergent taxa. Behavioral Ecology 15:679-686.

Hickerson, C.A., C.D. Anthony, and B.M. Walton. 2012. Interactions among forest floor guild members in structurally simple microhabitats. American Midland Naturalist 168:30-42.

Holt, R.D., and J.H. Lawton. 1994. The ecological consequences of shared natural enemies. Annual Review of Ecology and Systematics 25:495-520.

Homyack, J.A., E.B. Sucre, C.A. Haas, and T.R. Fox. 2010. Does Plethodon cinereus affect leaf litter decomposition and invertebrate abundances in mixed oak forest? Journal of Herpetology 44:447-456.

Jaeger, R.G. 1972. Food as a limited resource in competition between two species of terrestrial salamanders. Ecology 53:535-546.

Jaeger, R.G. 1980a. Microhabitats of a terrestrial forest salamander. Copeia 1980:205-208.

Jaeger, R.G. 1980b. Fluctuations in prey availability and food limitation for a terrestrial salamander. Oecologia 44:335-341.

Jaeger, R.G. 1990. Territiorial salamanders evaluate size and chitinous content of arthropod prey. Pp. 111-126 in R.N. Hughes (Ed.), Behavioral Mechanisms of Food Selection. NATO ASI Series, Subseries G: Ecological Sciences. Springer, Germany.

Jaeger, R.G., and D.E. Barnard. 1981. Foraging tactics of a terrestrial salamander: choice of diet in structurally simple environments. American Naturalist 117:639664.

Jaeger, R.G., and A.M. Rubin. 1982. Foraging tactics of a terrestrial salamander: judging prey profitability. Journal of Animal Ecology 51:167-176.

Jaeger, R.G., and S.E. Wise. 1991. A reexamination of the male salamander "sexy faeces hypothesis." Journal of Herpetology 25:370-373.

Jaeger, R.G., R.G. Joseph, and D.E. Barnard. 1981. Foraging tactics of a terrestrial salamander: sustained yield in territories. Animal Behaviour 29:1100-1 105.

Jaeger, R.G., D.E. Barnard, and R.G. Joseph. 1982. Foraging tactics of a terrestrial salamander: assessing prey density. American Naturalist 119:885-890.

Jaeger, R.G., K.C. Nishikawa, and D.E. Barnard. 1983. Foraging tactics of a terrestrial salamander: costs of territorial defense. Animal Behaviour 31:191-198.

Karuzas, J.M., J.C. Maerz, and D.M. Madison. 2004. An alternative hypothesis for the primary function of a proposed mate assessment behavior in Red-Backed Salamanders. Animal Behaviour 68:489-494.

Keen, W.H. 1984. Influence of moisture on the activity of a plethodontid salamander. Copeia 1984:684-688.

Kleeberger, S.R., and J.K. Werner. 1982. Home range and homing behavior of Plethodon cinereus in northern Michigan. Copeia 1982:409-415.

Langellotto, G.A., and R. Denno. 2004. Responses of invertebrate natural enemies to complex structured 
habitats: a meta-analytical synthesis. Oecologia 139:110 .

Langellotto, G.A., and R. Denno. 2006. Refuge from cannibalism in complex-structured habitats: implications for the accumulation of invertebrate predators. Ecological Entomology 31:575-581.

Lawrence, K.L., and D.H. Wise. 2000. Spider predation on forest floor Collembola and evidence for indirect effects on decomposition. Pedobiologia 44:33-39.

Lawrence, K.L., and D.H. Wise. 2004. Unexpected indirect effect of spiders on the rate of litter disappearance in a deciduous forest. Pedobiologia 48:149-157.

Lensing, J.R., and D.H. Wise. 2006. Predicted climate change alters the indirect effect of predators on an ecosystem process. Proceedings of the National Academy of Sciences of the United States of America 103:15502-15505.

Liebgold, E.B., and R.G. Jaeger. 2007. Juvenile movements and potential inter-age class associations of RedBacked Salamanders. Herpetologica 63:51-55.

Maglia, A.M. 1996. Ontogeny and feeding ecology of the Red-Backed Salamander, Plethodon cinereus. Copeia 1996:576-586.

Marsh, D.M., and M.A. Goicochea. 2003. Monitoring terrestrial salamanders: biases caused by intense sampling and choice of cover objects. Journal of Herpetology 37:460-466.

Mathis, A. 1990. Territoriality in a terrestrial salamander: the influence of resource quality and body size. Behaviour 112:162-175.

Mathis, A. 1991. Territories of male and female terrestrial salamanders: costs, benefits, and intersexual spatial associations. Oecologia 86:433-440.

Mathis, A., R.G. Jaeger, W.H. Keen, P.K. Ducey, S.C. Walls, and B.W. Buchanan. 1995. Aggression and territoriality by salamanders and a comparison with the territorial behaviour of frogs. Pp. 633-676 in H. Heatwole and B. Sullivan (Eds.), Amphibian Biology, Volume 2, Social Behaviour. Surrey Beatty and Sons, Australia.

McCann, K.S., J.B. Rasmussen, and J. Umbanhowar. 2005. The dynamics of spatially coupled food webs. Ecology Letters 8:513-523.

Miyashita, T., and S. Niwa. 2006. A test for top-down cascade in a detritus-based food web by litter-dwelling web spiders. Ecological Research 21:611-615.

Moore, A.L., C.E. Williams, T.H. Martin, and W.J. Moriarity. 2001. Influence of season, geomorphic surface and cover item on size and weight of Desmognathus ochrophaeus and Plethodon cinereus in Allegheny Plateau riparian forests. American Midland Naturalist 145:39-45.

Moore, J.C., D.E. Walter, and H.W. Hunt. 1988. Arthropod regulation of micro- and mesobiota in below-ground detrital food webs. Annual Review of Entomology 33:419-439.

Moran, M.D. 2003. Arguments for rejecting the sequential Bonferroni in ecological studies. Oikos 100:403405

Moulder, B.C., and D.E. Reichle. 1972. Significance of spider predation in the energy dynamics of forest floor arthropod communities. Ecological Monographs 42:473-498.
Murdoch, W.W. 1969. Switching in general predators: experiments on predator specificity and stability of prey populations. Ecology 39:335-354.

Nakagawa, S. 2004. A farewell to Bonferroni: the problems of low statistical power and publication bias. Behavioral Ecology 15:1044-1045.

[NRCS] National Resources Conservation Service, United States Department of Agriculture. 2012a. Web Soil Survey. Available at http://websoilsurvey.nrcs.usda.gov/. Archived by WebCite at http://www.webcitation.org/ 66nRgko5K on 9 April 2012.

[NRCS] National Resources Conservation Service, United States Department of Agriculture. 2012b. Official Soil Series Descriptions. Available at http://websoilsurvey. nrcs.usda.gov/technical/classification/osd/index.html. Archived by WebCite at http://www.webcitation.org/ 66nRs9c5G on 9 April 2012.

Ousterhout, B.H., and E.B. Liebgold. 2010. Dispersal versus site tenacity of adult and juvenile Red-Backed Salamanders (Plethodon cinereus). Herpetologica 66:268-275.

Petranka, J.W. 1998. Salamanders of the United States and Canada. Smithsonian Institution Press, USA.

Pfingsten, R.A., and F.L. Downs. 1989. Salamanders of Ohio. Ohio Biological Survey Bulletin New Series, Vol. 7, No. 2. The Ohio State University, USA

Pollierer, M.M., R. Langel, S. Scheu, and M. Maraun. 2009. Compartmentalization of the soil animal food web as indicated by dual analysis of stable isotope ratios $\left({ }^{15} \mathrm{~N} /{ }^{14} \mathrm{~N}\right.$ and $\left.{ }^{13} \mathrm{C} /{ }^{12} \mathrm{C}\right)$. Soil Biology and Biochemistry 41:1221-1226.

Richmond, L.S., and S.C. Trombulak. 2009. Distribution of Red-backed Salamander (Plethodon cinereus) with respect to cover-object characteristics in the Green Mountains of Vermont. Northeastern Naturalist 16:1326.

Rooney, N., K.S. McCann, and J.C. Moore. 2008. A landscape theory for food web architecture. Ecology Letters 11:867-881.

Rooney, T.P., C. Antolik, and M.D. Moran. 2000. The impact of salamander predation on Collembola abundance. Proceedings of the Entomological Society of Washington 102:308-312.

Sabu, T.K., R.T. Shiju, K.V. Vinod, and S. Nithya. 2011. A comparison of the pitfall trap, Winkler extractor and Berlese funnel for sampling ground-dwelling arthropods in tropical montane cloud forests. Journal of Insect Science 11:1-19.

Scheu, S. 2002. The soil food web: structure and perspectives. European Journal of Soil Biology 38:1120.

Schmidt, J.M., and A.L. Rypstra. 2010. Opportunistic predator prefers habitat complexity that exposes prey while reducing cannibalism and intraguild encounters. Oecologia 164:899-910.

Schultz, B.J., J.R. Lensing, and D.H. Wise. 2006. Effects of altered precipitation and wolf spiders on the density and activity of forest floor Collembola. Pedobiologia 50:43-50.

Seastedt, T.R. 1984. The role of microarthropods in decomposition and mineralization processes. Annual Review of Entomology 29:25-46.

Seastedt, T.R., and D.A. Crossley, Jr. 1981. Microarthropod response following cable logging and clear- 
cutting in the Southern Appalachians. Ecology 62:126135.

Sileshi, G. 2008. The excess-zero problem in soil animal count data and choice of appropriate models for statistical inference. Pedobiologia 52:1-17.

Spotila, J.R. 1972. Role of temperature and water in the economy of lungless salamanders. Ecological Monographs 42:95-125.

Swift, M.F., O.W. Heal, and J.M. Anderson. 1979 Decomposition in Terrestrial Ecosystems. University of California Press, USA.

Topping, C.J., and K.D. Sunderland. 1992. Limitations to the use of pitfall traps in ecological studies exemplified by a study of spiders in a field of winter wheat. Journal of Applied Ecology 29:485-491.

Walls, S.C., A. Mathis, R.G. Jaeger, and W.F. Gergits. 1989. Male salamanders with high quality diets have faeces attractive to females. Animal Behaviour 38:546548 .

Walton, B.M. 2005. Salamanders in forest floor food webs: environmental heterogeneity affects the strength of top-down effects. Pedobiologia 49:381-393.
Walton, B.M., and S. Steckler. 2005. Contrasting effects of salamanders on forest floor macro- and mesofauna in laboratory microcosms. Pedobiologia 49:51-60.

Walton, B.M., D. Tsatiris, and M. Rivera-Sostre. 2006. Salamanders in forest floor food webs: invertebrate species composition influences top-down effects. Pedobiologia 50:313-321.

Wise, D.H. 2004. Wandering spiders limit densities of a major microbi-detritivore in the forest floor food web. Pedobiologia 48:181-188.

Wootton, J.T. 1997. Estimates and tests of per capita interaction strength: diet, abundance, and impact of intertidally foraging birds. Ecological Monographs 67:45-64.

Wyman, R.L. 1998. Experimental assessment of salamanders as predators of detrital food webs: effects on invertebrates, decomposition and the carbon cycle. Biodiversity and Conservation 7:641-650. 